\title{
SAMBA E POLÍCIA: RESISTÊNCIA E CRÔNICAS COTIDIANAS DE UM OLHAR CONTRA-HEGEMÔNICO NA CIDADE DO RIO DE JANEIRO.
}

Samba and Police - everyday resistance and stories of a counter-hegemonic perspective in Rio de Janeiro city.

Barbosa, Eduardo Brasil eduardojuniorb@gmail.com orcid.org/0000-0002-0416-9394 


\section{RESUMO}

O Financiamento Público Educacional constitui um espaço de disputa de poder, onde a parte mais fraca é aquela que se cala, a dos financiados. No atual cenário brasileiro de recessão financeira anunciada, é urgente a reflexão sobre as questões que envolvem esse tema, do contrário, corremos o risco de perder recursos financeiros que, até então, após um histórico de luta, estiveram presentes no orçamento público das diversas esferas governamentais. Nesse contexto, aprofundase, aqui, essa discussão, levantando-se alguns aspectos históricos, orçamentários e educacionais e propondo uma reflexão crítica sobre o tema. Busca-se caracterizar a questão do Financiamento Público como um dos principais pilares de sustentação para uma educação pública capaz de combater o imobilismo que se instalou entre o poder dominante e os financiados e erguer uma bandeira revolucionária de discussão sobre o tema aqui proposto e sua responsabilidade com a Educação Básica Pública, vista como um ato político.

PALAVRAS-CHAVE: Financiamento da Educação Pública. Escola Pública. Educação.

\section{ABSTRACT}

Public Education Funding constitutes an area with dispute of power, where the weakest part, the financed, are the ones that have no say. In the current Brazilian scenario of the financial recession, it is a matter of urgency to reflect on the issues that are involved in this theme, otherwise we run the risk of losing financial resources that until then, after a history of struggle, was present in the public budget of various governmental spheres. In this context, we deepen this discussion, raising some historical, budgetary and educational aspects and propose a critical reflection on the theme. The aim is to characterize the theme of Public Funding as one of the main pillars of support for a public education able to combat the immobility that settled between the dominant power and the financed and to raise a revolutionary banner of discussion on the subject proposed here and its responsibility with Public Basic Education, seen as a political act.

KEYWORDS: Public Education Funding. Public School. Education. 


\section{Introdução}

O desafio de delimitar as raízes e as características do samba como elemento da cultura popular e de nossas matrizes identitárias movimentam o discurso sobre a hegemonia e aspetos de dominação de classes que influenciam diretamente a discussão sobre as origens de uma "autêntica" música popular brasileira. Sob uma perspetiva mais antropológica Hermano Vianna, em "O Mistério do Samba” (2007), desmonta teorias que focam no samba como forma cultural livre de negociações e de mediações culturais das diversas classes sociais no Brasil.

Vianna (ibid.) vê na rápida propagação do samba nas décadas de 1920 e 1930 elementos de pureza que garantiriam uma referência estável ao passado brasileiro e a nossa cultura popular, servido assim, aos interesses oficiais do Estado para inventar essa tradição. Expressando seu pensamento de forma figurada, Hermano Vianna constrói a narrativa sobre uma noitada de violão, em 1926, que reuniu, de um lado, Gilberto Freyre, Heitor Villa-Lobos, Sergio Buarque de Holanda, Prudente de Morais Neto - representantes da intelectualidade e de "boas famílias" brasileiras e, do outro lado, Patrício Teixeira, Donga e Pixinguinha - músicos jovens e negros saídos das camadas mais pobres da sociedade carioca (VIANNA, 2007, p. 20).

Tal encontro simboliza um fenômeno que posteriormente o samba amplifica para o discurso hegemônico nacional como um todo: a mestiçagem, o intercâmbio de classes e culturas, e a possibilidade de conviver pacificamente a despeito das diferenças e desigualdades como sendo a originalidade da experiência social brasileira. Neste enquadramento, decifrar "O Mistério do Samba" seria entender o processo de definição da identidade nacional brasileira.

O fato é que a verdade existente na história dos vencedores, ou a partir da perspectiva de Antonio Gramsci (1987), daqueles quem possuem a sua disposição os aparelhos de hegemonia, é por vezes, aquela que comprime a fala de um grupo subalterno. De tal modo que uma das questões a serem resolvidas nessa relação entre hegemonia e samba estaria no fato de como seria possível que a construção da identidade nacional fosse realizada a partir da incorporação de práticas culturais dos grupos subalternos.

Segundo Vianna (2007), a valorização do "popular" se dá na medida em que a relação entre a elite brasileira e a música popular passa a ser intermediada por indivíduos "que agem como mediadores culturais, e (...) espaços onde essas mediações são implementadas" (Idem, p. 41). Surge aí então a possibilidade de se relativizar a narrativa mítica sobre a origem de uma tradição, pois para Hermano Vianna (2007), o 
processo de consolidação do samba como símbolo de identidade nacional se calça em uma contradição social real: o discurso oficial que condena o popular como "pobreza cultural", mas que aplaude essa mesma cultura na vida cotidiana.

Em seu livro "Samba, o Dono do Corpo", Muniz Sodré (1998) não nega a existência de uma negociação e de um processo dialógico que levou à configuração do samba urbano da cidade do Rio de Janeiro como música símbolo da identidade nacional. Contudo, o seu trabalho parece privilegiar exatamente o componente contrário ao de Hermano Vianna, destacando o samba como elemento originado na cultura negra e em suas relações internas.

A imposição do samba como música urbana fundadora no Brasil deve-se muito mais à capacidade do negro em proteger e afirmar seu patrimônio cultural do que à síntese de um encontro multiétnico colaborativo. Segundo Muniz Sodré, uma resposta dançada de um indivíduo a um estímulo musical não se esgota numa relação de caráter técnico ou estético, uma vez que esta pode ser também um meio de comunicação com o grupo, uma afirmação de identidade social ou um ato de caráter religioso.

Sodré (1998) também expõe as desordens e os conflitos, muitas vezes, encobertos pelo discurso oficial, e é nesse sentido que a sua obra "Samba, o dono do corpo" se torna importante, pois ela nos traz a ideia de um relacionamento dialético entre as estruturas de origens negras que envolvem o samba, tal qual, entre o seu conteúdo e a sua forma.

Se por um lado o samba conseguiu se manter como traço expressivo dessa comunidade, mesmo diante dos inúmeros processos de segregação e dominação sobre o negro no início do século, por outro lado, é a voz do sambista a afirmação de uma cultura urbana em fase de industrialização e de inserção na engrenagem do capitalismo da primeira metade do século XX.

Gramsci (1987) considera que todos os homens preliminarmente são "filósofos" de uma "filosofia espontânea" peculiar a "todo o mundo", pois esta filosofia está contida na própria linguagem, no bom senso, no senso comum, que abrange todo um sistema de crenças, superstições, modos de ver e de agir que se manifestam naquilo que conhecemos geralmente por "folclore" (GRAMSCI, 1987, p. $11)$.

Quando o sambista imprime em suas canções marcas de sua própria personalidade e aspectos de uma consciência mais crítica, ele passa, enquanto cronista e compositor, a participar ativamente do processo de produção da história do mundo, pois ao adquirir consciência, os seus relatos apontam e denunciam as duras realidades impostas por um ambiente que lhe é exterior. Gramsci (1987) reafirma a "solidez das 
crenças populares" como elemento necessário para a concepção e fortalecimento de um bloco histórico, no qual a articulação popular, tem na maioria dos casos, a mesma energia de uma força material transformadora, sendo que a distinção entre forma e conteúdo seria algo puramente didático, uma vez que as forças materiais não seriam historicamente concebidas sem forma. E as ideologias e as crenças, por sua vez, sem aspectos e manifestações das forças materiais seriam meramente fantasias individuais (Idem, p. 63).

Ao refletir sobre aspetos relacionados à temática de Mídia e Cotidiano, elegemos como nosso objeto de estudo "O Samba", cujos versos presentes em suas canções têm como uma das suas principais características a letra como crônica da cidade do Rio de Janeiro e a sua cotidianidade ${ }^{22}$. Propomos a análise do Samba como resistência e discurso contra-hegemônico, pois, para além de um estilo musical capaz de dialogar com fatos e com os costumes, entendemos o samba carioca como um componente de questões profundas do espaço afetivo e de pertencimento, onde compositores e intérpretes agem como mediadores culturais num lugar social heterogêneo, de tensões, conflitos e confrontos e ao mesmo tempo lúdico, satírico e lírico.

Os vários discursos sobre o samba presentes na sociedade do Rio de Janeiro na virada do século XX para o século XXI, que se consubstanciam na fala de sambistas, são mais do que simples expressões de opiniões, e revelam a tentativa da legitimação de determinadas formas de expressão cultural. Dentre os diversos exemplos de sua apropriação, numa arena de disputas ideológicas e de construção social, podemos citar a própria utilização cultural realizada pelo regime de Vargas como propaganda política dos avanços desenvolvimentistas do Estado Novo ${ }^{23}$.

Tal apropriação e hegemonia sobre a cultura, bem como dos traços memorialísticos ajudam a reconstruir a identidade de um povo, sendo este não por acaso, um dos projetos civilizatórios encenados entre as décadas de 1930 até 1950 pelo Estado, que dispõe dos meios de repressão, que em última instância se expressam na coerção, ou seja, na derradeira estratégia de poder que os grupos dominantes utilizam para convencer e adquirir o consenso dos dominados.

Roberto DaMatta (1993) diz que basta mencionar um tema para encontrar uma

22 De acordo com Henri Lefebvre (1991, p.30), o cotidiano, se tomado como conceito teórico, seria uma espécie de fio condutor que permitiria conhecer a realidade social de uma dada época, pois é no cotidiano que "abstrações" como o Estado, a técnica, a cultura, as contradições sociais, se manifestam de forma concreta.

${ }^{23}$ Em dezembro de 1939, Getúlio Vargas cria o Departamento de Imprensa e Propaganda (DIP) com o propósito de difundir a ideologia do Estado Novo junto às camadas populares. Cabia ao DIP também, promover produções artísticas de interesse do Estado e censurar as que fossem contra esses mesmos interesses, como forma de controle da vida cultural de uma sociedade. 
canção popular que o comentou: “ (...) diante disso não deve ser por acaso que num país com altas taxas de analfabetismo, a música popular seja um veículo tão importante quanto a literatura nos países de cultura hegemonicamente burguesa" (DAMATTA; 1993, p. 61).

Através da análise crítica do discurso (FAIRCLOUGH, 2001) verificamos em letras de sambas como: Delegado Chico Palha (1938), Assim não Zambi (1979) e Numa Cidade Muito Longe Daqui - Polícia e Bandido de Arlindo Cruz (2009) aspectos de coerção e contra-hegemonia. Deste modo, faremos uso dos três sambas para construir a proposta de análise deste artigo, sobre a perspectiva da sobrevivência material e simbólica manifesta pelo povo subalternizado capaz de utilizar sua música como voz e expressão de valores críticos relacionados à sua própria cultura.

\section{Na época em que o samba era crime}

Assim que nasceu, no início do século XX, o samba ocupava com frequência os noticiários dos jornais. Os batuques só eram aceitos quando tocados por orquestras em roupagem folclórica e estilizada, nos teatros frequentados pela elite nacional. As rodas e batucadas improvisadas em bares, ou nas ruas da cidade do Rio de Janeiro, onde os sambistas negros e pobres tocavam tamborim, violão e pandeiro, eram tidas pela autoridade policial como vadiagem ou uma reunião de bandidos e desocupados. Muitas das vezes, seus participantes entre músicos e cantores, na sua grande maioria ex-escravos ou seus descendentes, acabavam sendo levados para a cadeia simplesmente por sambar.

Entre as diversas ocorrências publicadas no jornal Correio da Manhã, a do dia 09 de agosto de 1920 nos traz a imagem de como a polícia e a imprensa enxergavam os sambistas. Em uma nota foi divulgado que na tarde de domingo, vários "desocupados" formaram um "ruidoso samba" na Rua Visconde de Niterói, ao pé do Morro da Mangueira. Acionado, o delegado do $18^{\circ}$ Distrito foi ao local com o inspetor e outros policiais e "conseguiram prender parte do pessoal do batuque". A notícia termina informando também que foram apreendidos cinco pandeiros e um tambor (CORREIO DA MANHÃ, 09/08/1920).

Nem sempre, entretanto, as ações dos policiais eram recebidas sem uma reação contrária. Em dezembro de 1921, esse mesmo jornal relatava que policias do destacamento de Marechal Hermes, ao chegarem a um botequim em Bento Ribeiro para dar fim a um samba, frequentado por "indivíduos de má nota", foram recebidos a tiro. Houve confronto e no fim, quatro mulheres e quatro homens foram presos, 
dentre eles Tião da Favela, que resistiu à prisão dando cabeçadas e rasteiras nos policiais. O desfecho desta reportagem informa que Tião acabou dominado e conduzido ao xilindró (Idem, 02/12/1921).

No início do século XX, o simples fato de caminhar pelas ruas carregando um pandeiro, por exemplo, poderia levar uma pessoa para a cadeia, principalmente se o indivíduo fosse negro e se enquadrasse ou se vestisse tal qual um sambista ${ }^{24}$. Como não havia tipificações penais, as detenções realizadas pela polícia quase sempre atingiam grupos específicos como negros, ex-escravos, sambistas, praticantes de capoeira e adeptos das religiões afro como a umbanda e o candomblée ${ }^{25}$.

Agenor de Oliveira, mais conhecido como Cartola, nascido no Flamengo e criado no bairro de Laranjeiras, na Zona Sul carioca, aos 11 anos de idade se viu obrigado, por conta de uma de suas muitas adversidades financeiras, a se mudar para a região conhecida como Buraco Quente, um dos núcleos iniciais de povoamento do morro da Mangueira. Incapaz de participar das violentas "rodas de pernadas", Cartola realizou sua iniciação no samba através dos terreiros de umbanda, como cambono ${ }^{26}$ de rua da Tia Fé, preta velha fundadora do rancho Pérolas do Egito, e trabalhando também em busca das licenças oficiais da polícia para o desfile na Praça Onze.

Segundo Cartola, "naquela época, samba e macumba era tudo a mesma coisa" (SILVA, 2006, p. 65), na verdade como uma espécie de território sagrado, as casas de terreiro e santuários nagôs eram também espaços de proteção social que abrigavam trabalhadores da estiva, pretos velhos, tocadores de tambor, inveterados boêmios e capoeiristas procurados pela polícia.

Como locais de sociabilidade, sincretismo, religiosidade e festa, os terreiros eram espaços comunitários que subvertiam a sujeição dos corpos à lógica produtivista do mercado e à normatização dos comportamentos exigidos pelos novos tempos, ditos civilizados. Segundo Adalberto Paranhos (2005), ritmos como samba, macumbas e maxixes causavam nítido desconforto entre as elites sociais, daí, como rodas de samba não eram classificadas como crime pelos códigos penais de 1890 e 1942, os sambistas flagrados nesses tipos de aglomerações ou com seus instrumentos de baixo do braço, eram detidos pelos crimes de vadiagem.

Paranhos (2005) elucida como o contato do Estado com o samba carioca foi

${ }^{24}$ João da Baiana declarou que a polícia tomou seu pandeiro, sendo necessária a intervenção do senador Pinheiro Machado, que lhe repôs o instrumento com uma dedicatória, que lhe serviu como uma espécie de amuleto, contra futuras investidas policiais. In “As Vozes Desassombradas do Museu”. MIS, 1970, p. 80.

${ }^{25}$ Esta afirmação tem como base os estudos de Reinaldo Almeida Junior, doutor em direito pela Uerj e pesquisador da relação da lei com o samba e outros elementos da cultura afro. In:" Perseguido por décadas o samba chega ao centenário amado pelos brasileiros”. JORNAL O DIA de 27/11/2016. ${ }^{26}$ Trata-se de um auxiliar encarregado de, entre outras tarefas, montar despachos nas encruzilhadas. 
sendo realizado aos poucos, destacando a incorporação desse gênero à galeria de símbolos nacionais. No entanto, o autor deixa claro que nem todos os sambistas e compositores endossaram o coro das autoridades varguistas, apesar da história oficial defender o oposto, algumas vozes dissonantes de sambistas e da malandragem carioca resistiram quase que heroicamente a esse período.

Segundo o historiador, corremos o risco de superestimar o poder estatal no que tange à dominação das massas, pois "este é um processo dialético inserido no campo de lutas. Assim, intrínseco ao processo de dominação, sempre existe a resistência." (PARANHOS, 2005. p. 33). Para além disso, o conceito de hegemonia de Gramsci (1987) é interpretado por esse autor como algo que se modifica e se renova de acordo com as disputas políticas, ou seja, uma espécie de "equilíbrio de compromissos", onde o interesse e os valores das classes subalternas precisam, de certa forma, ser considerados em algum nível. Assim, a hegemonia convive com processos não hegemônicos, ou mesmo, contra-hegemônicos onde seus atores sociais estão em permanente interação através dos movimentos de assimilações, rejeições e também de imposições coercitivas.

\section{Delegado Chico Palha}

Regravado em DVD no ano de 2016 por Marcelo D2, o samba "Delegado Chico Palha", de autoria de Tio Hélio e Nilton Campolino, data originalmente de 1938 e, segundo as próprias palavras de seu intérprete, trata-se de uma história lá da Serrinha, contada mais ou menos assim:

Delegado Chico Palha (samba original de 1938)

In: Quintal Do Pagodinho 3 (Ao Vivo / Vol. 2) Universal Music International. 2016

"Delegado Chico Palha / Sem alma, sem coração.

Não quer samba nem curimba / Na sua jurisdição

Ele não prendia, só batia... (refrão)

Era um homem muito forte / Com um gênio violento

Acabava a festa a pau / E ainda quebrava os instrumentos

Ele não prendia, só batia... (refrão)

Os malandros da Portela, da Serrinha e da Congonha

Pra ele eram vagabundos / E as mulheres sem-vergonhas 
Ele não prendia, só batia... (refrão)

A curimba ganhou terreiro / O samba ganhou Escola

Ele expulso da polícia / Vivia pedindo esmola”

Ao final dessa gravação, D2 dirige-se a Zeca Pagodinho e estes iniciam o seguinte diálogo:

“ - Aê Pagodinho isso era 1938, hein !? (Marcelo D2)

- Mas ainda é a mesma coisa... (Zeca Pagodinho)

- Mas ainda é a mesma coisa, meu cumpadi... (Marcelo D2)

Samba e Curimba (ou seja, candomblé) não contavam com a simpatia das autoridades policiais, por este motivo organizavam-se em sua grande maioria na clandestinidade. Apesar da ausência de documentos oficiais que comprovem se o "Delegado Chico Palha" realmente tenha existido, é certo que se tratando de uma composição do ano de 1938, este samba pertence verdadeiramente a uma época onde a repressão às reuniões de batuque e a perseguição aos cultos afro-brasileiros eram realidades inseparáveis.

Para Eduardo Vidili (2018), as arbitrariedades e agressões cometidos pela figura policial, eternizadas na imagem do Delegado Chico Palha, eram corriqueiras, como os episódios de abusos de autoridade que estão relatados no exemplo, a seguir:

"Esses policiais, pelo fato de se acharem naquela rua tocando pandeiro três ou quatro dos moradores locais, praticaram coisas simplesmente indescritíveis, efetuando várias prisões, espancamentos populares, etc.” (VIDILI, 2018. p. 539). Tal trecho de matéria veiculada no em 6 de janeiro de 1917, elenca uma sucessão de desmandos da polícia que a partir de uma ordem de parar os "toques de pandeiro no meio da rua", seguiram-se a voz de prisão, uma fuga e perseguição, que culminou na invasão de um botequim e agressões físicas.

Os desmandos da polícia prosseguiam também na própria delegacia, pois nessa mesma reportagem as testemunhas que foram ao distrito policial denunciar a ação dos meganhas, ficaram à mercê, porque "recusou-se o comissário do dia a tomarlhes exatamente as declarações, procurando destarte, inocentar os policiais culpados" (CORREIO DA MANHÃ, 06/01/1917).

Para além de uma crônica que denuncia a ação policial carioca no cotidiano, o samba "Delegado Chico Palha" vai ao encontro de outros relatos como aquele registrado por Hildmar Diniz, o Monarco, que conforme depoimento para o documentário "Samba: 100 anos", diz que: 
"O samba foi muito marginalizado, as escolas de samba foram muito invadidas, a polícia dissolvia [sic] batia (...) um tal de Chico Palha, em Madureira, ele perseguia o sambista, não é? Batia, compreendeu? (...) Eu era garoto, estava cantando e brincando com os colegas daí passou um velhinho e: 'ah! Chico Palha aí...' E eu peguei e por que isso? Chico Palha, que negócio é esse que ele falou aí de Chico Palha?" e Monarco continua: "É um delegado que não gosta de samba, ele passava e dizia olha eu vou lá (...) e se eu voltar e encontrar isso ai já sabe.” (MONARCO, 05/12/2016)

Uma vez estabelecida a perseguição contra as rodas de batuque, o local mais seguro para as reuniões de pessoas das comunidades pobres passou a ser os terreiros e as casas de famílias, como por exemplo a casa de Tia Ciata, na Praça Onze, que segundo Sodré (1998, p. 15), foi um dos lugares mais importantes de resistência musical à ideia de marginalização contra o negro.

"Na sala de visitas, realizavam-se bailes (polcas, lundus, etc.), na parte dos fundos, samba de partido-alto ou samba-raiado, e no terreiro, batucada." (Idem, p. 16). Logo, o samba, não se configurava apenas como uma expressão musical ou dança, mas como instrumento de resistência sociocultural, de um grupo social marginalizado da vida urbana carioca e brasileira.

Assim "a Curimba ganhou terreiro e o samba ganhou Escola”, trata-se de uma conclusão ou "justiça poética", que guardada as devidas proporções, resgata a vingança do oprimido, em seu aspecto mais popular e simbólico. Analisando a última estrofe do samba aponta-se, portanto, para os ditos revezes da vida: capazes de consagrar a resistência e a vitória do samba sobre aquele delegado violento e opressor, ao qual coube ao destino se encarregar de privá-lo de um final feliz, uma vez que "Ele [o Delegado Chico Palha] expulso da polícia, vivia pedindo esmola".

\section{Assim não Zambi}

Zambi é o deus supremo de uma das vertentes do candomblé bantu, pela tradição oral, sabe-se que seu nome originalmente continha o sentido de "o senhor do mundo" (DIAS, 2011 p. 170) passando a designar posteriormente, não apenas um soberano "ser vivo", mas também um "Deus Supremo", provavelmente após as influências da cristianização do Reino do Congo. Influenciada pelas heranças dessa tradição, Clementina de Jesus, que é considerada por muitos como o elo perdido entre Brasil e África, interpreta em seu disco de 1979 a canção intitulada: 
Quando eu morrer

Vou bater lá na porta do céu

E vou falar pra São Pedro

Que ninguém quer essa vida cruel

Eu não quero essa vida assim não Zambi

Ninguém quer essa vida assim não Zambi

(falado) "Ô Zâmbi, vê se manda parar com aquelas brigas lá no morro. Quando os homens chegam, chutando as portas e revirando tudo. Todo mundo fica assustado, e a criançada com aqueles olhos arregalados, o coração saindo pela boca. Ai! Meu Deus. A tal de lei de invasão de domicílio, lá no morro, não vale nada."

Eu não quero essa vida assim não Zambi Ninguém quer essa vida assim não Zambi

(falado) “Ah! Zâmbi lembrei de outra coisa:

Vê se clareia a cabeça da minha gente lá do morro. Para eles pararem de tanta cachaçada, maconha e briga. Devagar, tá legal. Mas quando os negos estão doidos, dão tiro à toa à toa. $E$ quando eles inventam de brincar de bandido?
É o de baixo atacando o de cima, $O$ da direita atacando o da esquerda. E o pior é que ninguém é da direita nem da esquerda. É todo mundo do mesmo morro. É a miséria brigando com o miserê."

Eu não quero as crianças roubando As véinhas esmolando uma xepa na feira Eu não quero esse medo estampado

$\mathrm{Na}$ cara duns negos sem eira nem beira

Abre as cadeias pros inocentes

Dá liberdade pros homens de opinião

Quando um nego tá morto de fome

Um outro não tem o que comer

Quando o nego tá num pau-de-arara

Tem nego pensando num outro sofrer

Deus é Pai, Deus é filho,

Espírito Santo é Zambi

Eu não quero essa vida assim não Zambi Clementina é filha de Zambi

Eu não quero essa vida assim não Zambi

O Da Hora é filho de Zambi

Ninguém quer essa vida assim não Zambi Eu também sou filho de Zambi...

A crítica política e social é recorrente nas composições de Martinho da Vila e geralmente está relacionada com os temas da discriminação racial, da afirmação da cultura negra e das más condições de vida dos habitantes das favelas e das periferias das grandes cidades. Em Assim Não Zambi (1979), ele denuncia a situação dos afrodescendentes brasileiros, sujeitos à miséria e à repressão injusta da polícia. Assim 
como em Meu Homem, gravada por Beth Carvalho em 1988, Martinho da Vila tematiza a luta contra o apartheid e em "Kizomba, Festa da Raça", também de 1988, o sambista compõe o samba-enredo que exalta a luta dos negros pela liberdade.

Quando Martinho da Vila e Clementina de Jesus dialogam declarando que: "Quando os homens chegam, chutando as portas e revirando tudo. Todo mundo fica assustado, a criançada com aqueles olhos arregalados, o coração saindo pela boca" (ambos estão se referindo às práticas policiais repressivas, realizadas nos morros e favelas da cidade do Rio de Janeiro, que naquele momento estava condicionado a uma ditadura militar, governada à época por Ernesto Geisel (1974 - 1979). Todavia, Geisel foi considerado por muitos o precursor do processo de distensão do regime, mas também o sucessor imediato de uma política "linha dura" herdada de Emílio Garrastazu Médici (1969-1974), que desenvolveu uma forte repressão, destacando-se a perseguição, prisão e tortura de "subversivos" nas mais diversas esferas sociais.

“Ai! Meu Deus. A tal de lei de invasão de domicílio, lá no morro, não vale nada.", denuncia o sambista relatando um fato corriqueiro no cotidiano das comunidades que se estende até hoje, quando se fala em práticas de repressão policial. $\mathrm{O}$ fato é que, embora a jurisprudência autorize a abordagem policial em via pública para averiguação, não é, isoladamente, justa a causa para a polícia entrar nas casas sem o mandado, ou consentimento dos moradores do local.

"Ah! Zâmbi lembrei de outra coisa: Vê se clareia a cabeça da minha gente lá do morro. Para eles pararem de tanta cachaçada, maconha e briga. Devagar, tá legal. Mas quando os negos estão doidos, dão tiro à toa à toa. E quando eles inventam de brincar de bandido?”. O período histórico em questão coincide com a expansão da violência e a associação dos bandidos cariocas aos narcotraficantes e aos carteis internacionais da Bolívia e Colômbia sendo, portanto:

\footnotetext{
Neste contexto que os emissários do Cartel de Medelin de Escobar decidem transformar Rio de Janeiro em um centro consumidor (...) Escobar mandou oferecer cocaína colombiana super-refinada a preço de custo, de forma que, por ser muito barata, a cocaína passou a ser consumida ostensivamente. Esta operação - conhecida por "Natal de neve" - deu resultados imediatos, inclusive porque o lucro era muito alto, o risco físico era bastante limitado e as "doações" (o arrego) para policiais corruptos eram ainda de baixo valor. O surgimento deste mercado ilegal modificou a estrutura do crime organizado no Rio, com os principais bandos de assaltantes ou de sequestradores ligados ao Comando Vermelho que se reciclaram por se tornar traficantes e distribuindo com equidade os territórios do novo mercado. (LIMA, 2011, p. 44)
}

"É o de baixo atacando o de cima, O da direita atacando o da esquerda. E o pior é que ninguém é da direita nem da esquerda. É todo mundo do mesmo morro". A partir da década de 1980 já não havia mais como as autoridades negarem a existência 
das organizações criminosas.

O conflito entre essas organizações, bem como o fortalecimento de cada uma delas, é tão real que nos presídios havia a necessidade de separar os presos de acordo com o vínculo que estes possuíam com cada organização. Caso contrário, não sendo feita esta separação, o membro de uma facção colocado entre os membros de outra era brutalmente assassinado. Segundo o historiador Fábio de Lima (2011), uma outra característica marcante do período é que enquanto o Comando Vermelho passa ter como seu maior negócio o tráfico de drogas, simultaneamente, as demais facções, passam a investir no tráfico de armas, o que ocasionará o aumento do poderio bélico das favelas cariocas. O uso do fuzil automático sempre foi a opção tática preferida dos criminosos. Curiosamente em várias situações, diferentes facções criminosas chegaram a ser abastecidas por fuzis e outros equipamentos militares por um único grande fornecedor. Era notável que, algumas vezes, criminosos davam muito dinheiro para comprar armas defeituosas e que não sabiam operar, apenas para que esse armamento não viesse a cair em mãos adversárias (Idem, p. 130). Isso é, realmente, a miséria brigando com o miserê.

Como diz a música, uma vida cruel, onde há repressão, abusos policiais, invasões de domicílios, brigas entre bandidos, além de crianças roubando e velinhas esmolando por si só, já era uma letra que registrava a opressão e a situação daqueles que viviam no morro em meio ao regime militar. Este samba também foi motivo de preocupação para Clementina de Jesus, devido ao caráter de alguns versos como: “Abre cadeia pros inocentes / Dá liberdade pros homens de opinião". "Isso não vai me dar problemas?", perguntava. (CASTRO. 2017, p 257).

Para Castro, o questionamento de Clementina de Jesus revela a relação de Assim Não Zambi ao contexto histórico-social, onde o eu lírico além de denunciar os abusos sofridos pelas comunidades nos morros cariocas, traz também consigo outras questões ligadas a esfera das relações sociais intra e interclasses. Com uma narrativa confessional e um apelo melancólico e pessimista, o homem pobre e oprimido é subjugado pelas mais diversas formas de dominações que são vividas pelo sujeito: “Quando um nego tá morto de fome / Um outro não tem o que comer / Quando o nego tá num pau-de-arara / Tem nego pensando num outro sofrer”.

Longe de traduzir uma posição conformista em relação às agruras da vida, quando o sambista inicia seu diálogo com Zambi, ele mesmo se questiona se o sofrimento vivido pode ser considerado uma experiência natural e adequada aos desígnios superiores do destino humano. Ao denunciar sua revolta diante de tamanhas aflições, o sambista reconhece que se encontra duplamente oprimido: tanto espiritualmente pelo destino, quanto materialmente pela exploração. 


\section{Numa Cidade Muito Longe Daqui}

O aumento dos índices de criminalidade e a explosão registrada pela violência urbana na cidade do Rio de Janeiro, durante as décadas de 1980 e 1990, são consequências diretas da expansão do chamado "crime organizado", fruto da associação entre bandidos detidos pela Lei de Segurança $\mathrm{Nacional}^{27}$ e narcotraficantes que lotearam os espaços urbanos, além de morros e favelas do Rio de Janeiro e começaram a dar origem as facções criminosas tais como: Comando Vermelho, Terceiro Comando, Amigos dos Amigos, entre outras diversas denominações.

É nesse contexto que "Numa Cidade Muito Longe Daqui" é composta. Como uma espécie de "tiro a queima roupa" usando as próprias palavras de um de seus autores, o sambista Arlindo Cruz explica que sua intenção com a música era: “... questionar quem é o principal culpado desta guerra entre polícia e Bandido”. De forma melódica, o autor descreve o que acontece no dia a dia de quem mora em favela e precisa se acostumar com as abordagens policiais.

Em entrevista contida nos bastidores da gravação do álbum ao vivo para a MTV (2009), Arlindo Cruz reproduz uma fala que reforça a nossa tese onde as letras de samba tornam-se um espaço contra-hegemônico, onde o sambista, através de suas crônicas, denuncia questões e injustiças sociais e particularidades da cidade em forma de canção:

A composição vem naturalmente, na rua, na praia, vendo TV... Nós, sambistas, somos meio cronistas do dia a dia. Numa Cidade Muito Longe Daqui (Polícia e Bandido) demorou a sair. A gente recebe os personagens e as histórias e repassa por forma de canção. Mas muita coisa a gente cria também. Eu lembro que quando fiz "Numa cidade muito longe daqui", eu contava a história do bandido e a polícia, que depois de trocarem tiros e farpas, foram atendidos na mesma ambulância. Meses depois, aconteceu um confronto no Rio de Janeiro da mesma forma. Por incrível que pareça, foi uma coincidência. (ARLINDO CRUZ, 2009)

O enredo se desdobra depois de uma troca de tiros, onde dois ensanguentados

\footnotetext{
${ }^{27}$ As quadrilhas de assaltantes especializadas também no roubo a bancos, já assaltavam em paralelo a empreitada guerrilheira após o AI-5 e foram incluídos na mesma Lei de Segurança Nacional aplicada à esquerda armada. Nas penitenciárias, estes homens se distinguiam dos demais marginais sob o rótulo de "os lei de segurança". Então numa posição intermediária entre o marginal dos anos 50 e 60, de extração social favelada, e o guerrilheiro "terrorista" dos anos 70, oriundo da classe média, esses detidos pela Lei de Segurança Nacional (LSN) tais marginais vão obtendo, nas penitenciárias, o respeito de antigos criminosos e a solidariedade de parte dos guerrilheiros e demais presos políticos. In: BARBOSA JR, E. B. "Mídia e auto-representação: da malandragem carioca dos anos 30 até a exposições nas redes sociais da “Geração Z”. ALAIC, UFF, Niterói, 2019. No prelo.
} 
(um policial e um traficante) se provocam: "Você levou tanto dinheiro meu / Agora vem querendo me prender", reclama o criminoso. A música, que ganhou clipe rodado numa favela, com cena de policial recebendo dinheiro de bandido, nos traz a reflexão de papéis que se invertem de maneira que "tem homem da lei que vira homem mau" e "tem homem mau que vira homem bom".

\author{
Numa Cidade Muito Longe Daqui - Polícia e Bandido de Arlindo Cruz
}

IN: ARLINDO CRUZ - "MTV ao Vivo Arlindo Cruz" Deckdisc. 2009

Um dia o bicho pegou, o coro comeu, Polícia e Bandido se encontraram e bateram de frente E aí rapaziada, foi chapa quente, chapa quente,

\section{Chapa quente}

Bateu de Frente

O bandido e o subtenente lá do batalhão

foi tiro de lá e de cá

balas perdidas no ar

Até que o silêncio gritou,

Dois corpos no chão, que azar

Feridos na mesma ambulância

Uma dor de matar

Mesmo mantendo a distância

Não deu pra calar

Polícia e Bandido trocaram farpas

Farpas que mais pareciam balas

E o bandido falou assim:

(bandido) - Você levou tanto dinheiro meu e agora vem querendo me prende;

(polícia) - Eu te avisei você não se escondeu, deu no que deu e a agente está aqui;

- Pedindo a Deus para o corpo resistir, será que ele está a fim de ouvir?

(polícia) - Você tem tanta bazuca, pistola, fuzil e granada. Me diz pra que tu tem tanta munição?

(bandido) - É que além de vocês nós ainda enfrentamos um outro comando, outra facção

- Só tem alemão sanguinário, um bando de otário, marrento querendo zoar;

- Por isso eu tô bolado assim;

(polícia) - Eu também tô bolado sim

- É que o judiciário tá todo comprado, e o legislativo tá financiado e o pobre operário que jogo o seu voto no lixo, não sei se por raiva ou só por capricho;

- Coloca a culpa de tudo nos homens do camburão

- Eles colocam a culpa de tudo na população (bandido) - E se eu morrer vem outro em meu lugar

(polícia) - E se eu morrer vão me condecorar (bandido) - E se eu morrer será que vão lembrar (polícia) - E se eu morrer será que vão chorar (bandido) - E se eu morrer ... (polícia) - E se eu morrer ...

Chega de ser subjulgado, subtraído e subnutrido, Um sub-bandido de um sub-lugar, Um subtenente de um sub-país, sub infeliz Mas essa estória eu volto a repetir;

Aconteceu numa cidade muito longe daqui; Que tem favelas que parecem as favelas daqui Que tem problemas que parecem os problemas daq 


\section{Conclusão}

Como fica claro nos três sambas mencionados nesse artigo: Delegado Chico Palha (1938), Assim não Zambi (1979) e Numa cidade muito longe daqui - Polícia e Bandido (2009), é no cenário das favelas e das comunidades pobres cariocas que a violência policial indiscriminada permanece rotineira, ao mesmo tempo em que as instituições da sociedade política, como o braço armado do Estado, reduzem a participação popular para um universo cada vez mais estreito e segregador, estreitando significativamente os horizontes democráticos. Esse é o processo, que Antonio Gramsci (1964) atribui ao Estado em seu sentido mais amplo de "ditadura + consenso", ou seja, "a hegemonia revestida de coerção" (Ibid. p. 172).

Ao refletirmos sobre o papel da polícia em uma sociedade democrática de direito, percebemos que a violência policial é o traço em comum e fio norteador dos três sambas analisados para esse artigo. E, em todos os casos, a violência se impõe como um contraponto às narrativas de um processo civilizador e democratizante, pois ao invés de garantir a ordem pública e mediar os conflitos, a violência policial acaba por causar graves transtornos.

Sem os meios materiais capazes de amplificar e fazer ecoar a sua voz, a população dos morros e subúrbios cariocas, com raras exceções, não dispõe dos instrumentos mais eficazes de criação e expressão de uma consciência alternativa. Neste sentido, o samba se torna uma das principais formas contra-hegemônicas de comunicação e denúncia dos oprimidos, pautado em suas experiências cotidianas, nos espaços de representação e convivência coletiva, e acima de tudo, no exercício e manutenção da cultura popular baseada fundamentalmente na tradição oral.

Por mais que a repressão física e simbólica seja parte inerente à história do samba, tais aspectos repressivos, não conseguiram calar a voz de revolta desses homens comuns, expressa na obra e na arte descrita pelas mãos do sambista. É nesse ritmo insurgente que a voz do oprimido ganha a sua força inusitada, capaz de irromper nas frestas do discurso dominador. 